\title{
Stereospecific Transport of Triiodothyronine from Plasma to Cytosol and from Cytosol to Nucleus in Rat Liver, Kidney, Brain, and Heart
}

\author{
J. H. Oppenheimer and H. L. Schwartz \\ Division of Endocrinology and Metabolism, Department of Medicine, University of Minnesota, Minneapolis, Minnesota 55455
}

\begin{abstract}
We have investigated the transport of $L$ - and D-triiodothyronine $\left(T_{3}\right)$ from plasma to cellular cytoplasm and from cytoplasm to nucleus by estimating the concentration of free hormone in these compartments in rat liver, kidney, brain, and heart. We assessed the distribution of $T_{3}$ in various tissues and its metabolism by standard isotopic techniques and measured plasma and cytosolic tissue $T_{3}$ by radioimmunoassay. In addition, we determined the fraction of radioactive $T_{3}$ associated with the cytosol in individual tissues and estimated the cytosolic volume per gram of tissue. Equilibrium dialysis allowed us to determine the binding power of cytosols and plasma, and in vitro saturation techniques provided values for the affinity $\left(k_{\mathbf{a}}\right)$ for $L-$ and $D-T_{3}$ of isolated nuclei in aqueous solution at $37^{\circ} \mathrm{C}$. We calculated the free cytosolic hormone from the product of cytosolic $T_{3}$ and the binding power of cytosol for $T_{3}$, and the free intranuclear $T_{3}$ from the $k_{n}$ and previously determined ratio of occupied-to-unoccupied binding sites under steady state conditions in euthyroid animals. Our results showed that the free cytosolic/free plasma concentrations for $L-T_{3}$ and $D-T_{3}$, respectively, were: liver $2.8,21.6$; kidney 1.17, 63.3; heart 1.31, 1.58; brain 0.86, 0.24 . The free nuclear/free cytosolic ratios for $L-T_{3}$ and $D-T_{3}$, respectively, were: liver 58.2, 3.70; kidney 55.9, 1.54; heart 80.6, 24.9; and brain 251, 108.6. Our findings suggest that stereospecific transport occurs both from plasma to cytosol and from cytosol to nucleus. The high gradients from cytosol to nucleus imply that there is an energydependent process and appear to account for the differences in the nuclear association constant determined in vivo and in vitro.
\end{abstract}

\section{Introduction}

Although there is substantial evidence pointing to a rapid exchange of triiodothyronine $\left(T_{3}\right)^{l}$ between plasma and cellular pools and among subcellular components (1), the basic mechanisms responsible for the establishment of such equilibrium relationships remain ill-defined. In particular, there has been considerable controversy as to whether the exchange of $T_{3}$ between cells and their milieux is a function of simple diffusion or whether mediated transport, either active or facilitated, is involved. Lein and Dowben (2) at first proposed that because of the lipophilic properties of $T_{3}$, the partition between $T_{3}$ and

Received for publication 15 June 1984 and in revised form 27 August 1984.

1. Abbreviations used in this paper: $\mathrm{T}_{3}$, triiodothyronine; $\mathrm{T}_{4}$, thyroxine.

J. Clin. Invest.

(C) The American Society for Clinical Investigation, Inc.

$0021-9738 / 85 / 01 / 0147 / 08 \quad \$ 1.00$

Volume 75, January 1985, 147-154 cells could be explained by simple diffusion. On the other hand, Rao and co-workers $(3,4)$ have challenged this viewpoint and have concluded from their studies in isolated hepatocytes that, in part, such transfer represents a saturable process which can be retarded by certain metabolic inhibitors. Krenning and colleagues have reached essentially similar conclusions $(5,6)$. More recently Cheng et al. have proposed that in cultured fibroblasts receptor-mediated transport is involved in the exchange process $(7,8)$. The applicability of these findings to the exchange process that occurs in vivo however, has not been specifically examined.

In contrast, it is generally agreed that the equilibration between nucleus and cells is determined by simple diffusion, and the steady state partition by the binding characteristics of the individual compartments. Studies with isolated nuclei have failed to reveal a requirement for a specialized transport system or the expenditure of metabolic energy (9). However, it is not clear whether this in vitro model is applicable to the in vivo processes in the intact animal.

Recent experiments with ${ }^{125} \mathrm{I}$-labeled $\mathrm{D}$ - and $\mathrm{L}-\mathrm{T}_{3}$ in our laboratory have stimulated our interest in examining both of these questions (10). These studies showed a high degree of stereospecificity in the entrance of $L-$ and $D-T_{3}$ into various tissues. Our studies also showed for the first time that there is a remarkable degree of specificity in the accumulation of $\mathrm{L}-$ as compared with $\mathrm{D}-\mathrm{T}_{3}$ by nuclei of various cells in the intact animal. These observations contrasted strongly with the relative lack of specificity in the binding of these enantiomers in vitro. The enhanced accumulation of $L-T_{3}$ in vivo appeared to account for the greater biologic potency of the L-form.

Since both enantiomers of $T_{3}$ have similar physical and chemical characteristics, it occurred to us that these substances could be used as effective probes in examining the mechanism that underlies $T_{3}$ transport and exchange processes. Furthermore, by estimating the concentration of free hormone in plasma, cytosol, and nucleus we attempted to determine the presence or absence of significant gradients, which might reflect the participation of active metabolic processes in transport.

\section{Methods}

Male Sprague-Dawley rats weighing 175-200 $\mathrm{g}$ were purchased from BioLab Corp. (St. Paul, MN). The animals had free access to food (Purina rat chow; Ralston Purina Co., St. Louis, MO) and water [ ${ }^{125} \mathrm{I}_{\mathrm{L}}-\mathrm{T}_{3}$ was purchased from Abbott Laboratories (North Chicago, IL). $\left.{ }^{125} \mathrm{I}\right] \mathrm{D}-\mathrm{T}_{3}$ was prepared for us by the same supplier through the courtesy of Mr. B. J. Green. Purity of isotopic preparations was assayed by paper chromatography with $t$-amyl alcohol-hexane-ammonia (11). All preparations were $>90 \%$ pure and contained $<2 \%\left[{ }^{125} \mathrm{I}\right] \mathrm{T}_{4}$. The only other detectable contaminant was [ $\left.{ }^{125} I\right]$ iodide. Enantiomeric purity was determined by the high-performance liquid chromatographic procedure of Hay et al. (12). Cross contamination was no greater than $1-2 \%$.

Concentration ratios of $\left[{ }^{125} I\right] \mathrm{L}$ or $\left[{ }^{125} \mathrm{I}\right] \mathrm{D}-\mathrm{T}_{3}$ in plasma, tissues, and nuclei were determined as previously described (13). Tracer doses $(<5$ 
$\mathrm{ng} / 100 \mathrm{~g}$ body $\mathrm{wt}$ ) were injected via the tail vein. Animals were killed at intervals from $5 \mathrm{~min}$ to $24 \mathrm{~h}$. Blood was collected from the abdominal aorta and tissues were excised. Plasma $\left[{ }^{125} \mathrm{I}\right] \mathrm{T}_{3}$ concentrations were determined in TCA-treated samples. We recently demonstrated that there are no systematic differences between results obtained with the TCA procedure and those obtained with other standard methods for separation of the $\left[{ }^{125} \mathrm{I}\right] \mathrm{T}_{3}$ from other ${ }^{125} \mathrm{I}$-labeled products in plasma (10). Tissues were homogenized in $0.32 \mathrm{M}$ sucrose- $3 \mathrm{mM} \mathrm{MgCl}$ and nuclei were prepared by centrifugation through $2.4 \mathrm{M}$ sucrose. The composition of the ${ }^{125}$ I-labeled compounds in aliquots of homogenate from the several tissues was analyzed by paper chromatography (11). Since $\left.{ }^{125} \mathrm{I}\right] \mathrm{T}_{3}$ accounted for $\sim 90 \%$ of the total, no correction was made in calculating the tissue/plasma isotopic concentration ratios. Concentrations of $\left[{ }^{125} \mathrm{I}\right] \mathrm{L}-$ or $\left[{ }^{125} \mathrm{I}\right] \mathrm{D}-\mathrm{T}_{3}$ observed in brain and heart were corrected for that fraction associated with plasma trapped within the tissue. The volume of trapped plasma per gram of tissue was assayed after intravenous injection of ${ }^{125} \mathrm{I}$-albumin into a separate group of rats. The volumes measured in milliliters per gram were: brain, 0.024; heart, 0.117; kidney, 0.102; and liver, 0.102. For liver and kidney the binding for $T_{3}$ was strong enough so that the correction was $<2 \%$ and could be safely ignored. Levels of nonspecifically bound ${ }^{125}$ I-labeled hormone in nuclei were determined for all tissues in animals injected with loading doses, $20 \mu \mathrm{g} / 100 \mathrm{~g}$ body wt, of unlabeled hormone together with the radiolabeled tracer dose and killed $3 \mathrm{~h}$ later. The nuclear/plasma isotopic concentration ratio measured in this group was then subtracted from that observed at all times. The corrected nuclear/plasma isotopic ratio was taken to represent the ratio of specifically receptor bound $T_{3}$ in the nucleus to that in plasma. DNA concentrations were measured by the Burton procedure as modified by Giles and Meyers (14).

In order to determine the fraction of intracellular $\left[{ }^{125} \mathrm{I}\right] \mathrm{L}-$ or $\left[{ }^{125} \mathrm{I}\right] \mathrm{D}$ $T_{3}$ associated with cytosol, animals were injected intravenously with tracer doses ( $<5 \mathrm{ng} / 100 \mathrm{~g}$ body $\mathrm{wt}$ ) of one radiolabeled enantiomer or the other. After $2 \mathrm{~h}$, rats were killed and tissues excised. 10\% homogenates were prepared in $0.32 \mathrm{M}$ sucrose- $3 \mathrm{mM} \mathrm{MgCl}$ and an aliquot was taken for radioactive assay. Cytosol was prepared by centrifugation in a $70.1 \mathrm{Ti}$ rotor at $160,000 \mathrm{~g}$ for $60 \mathrm{~min}$. The clear cytosol was separated and a measured aliquot was counted. All procedures were carried out at $2-4^{\circ} \mathrm{C}$. Again, corrections were made in brain and heart for trapped plasma under the assumption that all plasma would be associated with the cytosol fraction.

Equilibrium dialysis was performed as previously described (15). Plasma was diluted threefold with $0.15 \mathrm{M}$ sodium phosphate buffer, pH 7.4, and $0.1 \mu \mathrm{Ci}\left[{ }^{125} \mathrm{I}\right] \mathrm{L}-$ or $\left[{ }^{125} \mathrm{I}\right] \mathrm{D}-\mathrm{T}_{3}$ added. Duplicate $2-\mathrm{ml}$ aliquots were then dialyzed for $18-20 \mathrm{~h}$ at $37^{\circ} \mathrm{C}$ against $4 \mathrm{vol}$ of the same buffer. Cytosol was prepared by homogenization of $1 \mathrm{~g}$ of tissue with $19 \mathrm{vol}$ of the buffer and centrifugation at $160,000 \mathrm{~g}$ for $60 \mathrm{~min}$. After the addition of $\left[{ }^{125} \mathrm{I}\right] \mathrm{L}$ - or $\left[{ }^{125} \mathrm{I}\right] \mathrm{D}-\mathrm{T}_{3}$, duplicate 2 -ml aliquots of cytosol were dialyzed for $18-20 \mathrm{~h}$ at $37^{\circ} \mathrm{C}$ against 3 vol of buffer.

The volume of cytosol contained in a gram of tissue was measured by isotopic dilution. $1 \mathrm{~g}$ of tissue was homogenized in $3 \mathrm{ml}$ of $0.32 \mathrm{M}$ sucrose-3 $\mathrm{mM} \mathrm{MgCl}$ containing $0.1 \mu \mathrm{Ci}$ of ${ }^{125} \mathrm{I}$-albumin. The homogenate was centrifuged at $160,000 \mathrm{~g}$ for $60 \mathrm{~min}$ and $1 \mathrm{ml}$ of the clear supernatant was taken for radioactive assay. Since essentially all labeled albumin is distributed to the cytosol, the ratio of the ${ }^{125} \mathrm{I}$-albumin added in the starting homogenizing medium to the final cytosolic concentration yields the volume of cytosol.

Assays of nuclear $T_{3}$ receptor were performed as described by Schuster et al. by the use of isolated nuclei (16). Binding capacity and association constants were calculated from Scatchard analyses of the binding data.

\section{Calculations}

The model system used for the interrelationship between cells and plasma and between nuclei and cytosol is based on generally accepted views and is schematically represented in Fig. $1(17,18)$.

Concentration gradients of free $T_{3}$ between cytosol and plasma.

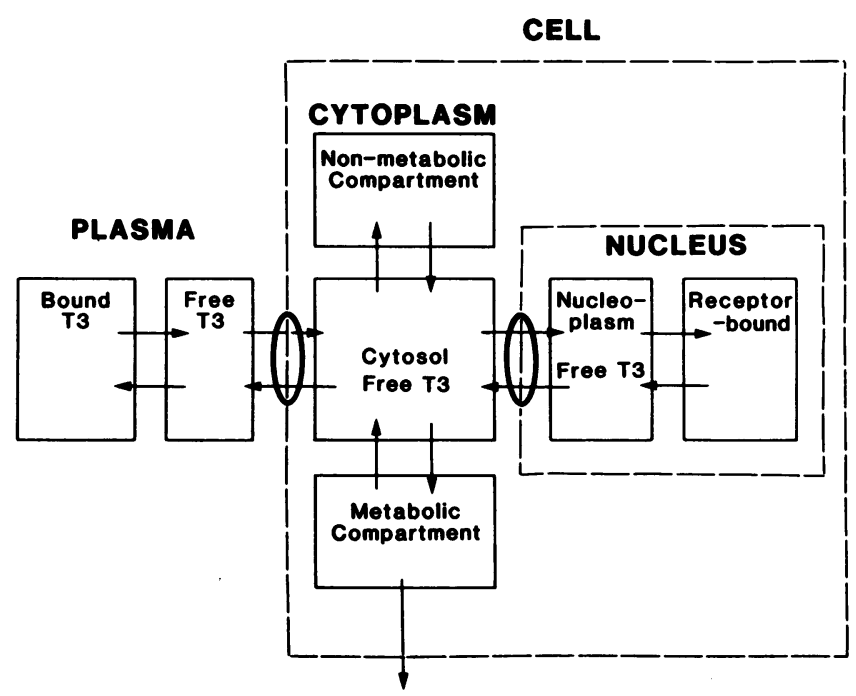

Figure 1. Schematic representation of equilibrium relationships of $T_{3}$ between plasma and cytosol and between cytosol and other cellular compartments. Circled exchange arrows represent putative transport systems under consideration in this study.

The tissue/plasma isotopic concentration ratio $\left(T^{*} / P^{*}\right)$ was calculated for each tissue at the equilibrium time point, previously defined as the peak value in the nuclear radioactivity concentration curve (13). At this point, the specific activity of plasma-derived $T_{3}$ and tissue $T_{3}$ can be presumed to be identical, and the nonradioactive tissue/plasma concentration ratio, $T / P$, to equal ${ }^{*} T /{ }^{*} P$. Because there is a broad plateau achieved by brain and heart, the values between 1 and $6 \mathrm{~h}$ were averaged.

We have previously (19) defined the binding power $\left(b_{p}\right)$ per gram as $(1-D F / D F) \gamma$, where $D F$ is the dialysis fraction of the serum, and $\gamma$ is the dilution factor. One can define the binding power of cytosol, $b_{\mathrm{c}}$, in an analogous fashion. $1 \mathrm{~g}$ of tissue was diluted 20-fold during homogenization and the cytosol was diluted 4-fold more for dialysis. Since the cytosol constitutes only a fraction of the tissue radioactivity, the value $80 / V_{c}$ was assumed to be $\gamma$, where $V_{c}$ is the estimated volume of the cytosol per gram tissue. Theoretical considerations suggest that the binding power is proportional to dilution (20), and this was confirmed by the demonstration of comparable binding power values when $1 \mathrm{~g}$ of homogenate was brought to both 40 and $80 \mathrm{ml}$. The fraction of total radioactive $T_{3}$ associated with the cytosol, $\rho_{c}$, was determined by subcellular fractionation as described above. We calculated the gradients of free cytosolic $\mathrm{T}_{3}, F_{\mathrm{c}}$, to the concentration of free hormone in plasma, $F_{\mathrm{p}}$, as follows:

$\frac{F_{\mathrm{c}}}{F_{\mathrm{p}}}=\frac{T \cdot \rho_{\mathrm{c}} \cdot \frac{1}{V_{\mathrm{c}}} \cdot \frac{1}{b_{\mathrm{c}}}}{P \cdot \frac{1}{b_{\mathrm{p}}}}=\frac{T^{*} \rho_{\mathrm{c}} b_{\mathrm{p}}}{P^{*} V_{\mathrm{c}} b_{\mathrm{c}}}$.

If we assume that $T / P=T^{*} / P^{*}$ and since

$b_{\mathrm{c}}=\frac{1-D F_{\mathrm{c}}}{D F_{\mathrm{c}}} \cdot \frac{80}{V_{\mathrm{c}}}$,

where $\mathrm{DF}_{\mathrm{c}}$ is the dialysis fraction of cytosol, it follows that

$\frac{F_{\mathrm{c}}}{F_{\mathrm{p}}}=\frac{T^{*} \rho_{\mathrm{c}} b_{\mathrm{p}}}{80 P^{*} \cdot \frac{1-D F_{\mathrm{c}}}{D F_{\mathrm{c}}}}$.

Thus, the ratio $F_{\mathrm{c}} / F_{\mathrm{p}}$ does not depend upon determination of $V_{\mathrm{c}}$. 
Measurement of the free cytosolic $T_{3}$ concentration by radioimmunoassay (RIA) and isotopic techniques. Four animals were injected with tracer $\left[{ }^{125} \mathrm{I}\right] \mathrm{T}_{3}$ and killed $2 \mathrm{~h}$ later. At this point the tissue/plasma ratio is not different from that at the equilibrium time point for liver, and the level of radioactive $T_{3}$ in other tissues is close to the equilibrium time point. These considerations allow the assumption of identical specific activities for plasma-derived tissue $T_{3}$ and plasma $T_{3}$. Liver, heart, brain, and kidney were excised and $1 \mathrm{~g}$ of tissue was homogenized with $4 \mathrm{ml}$ of $0.32 \mathrm{M}$ sucrose-3 $\mathrm{mM} \mathrm{MgCl}_{2}$. Cytosol was prepared as described above. An aliquot of cytosol and serum was taken for assay of total ${ }^{125}$ I content. A second aliquot was extracted with absolute ethanol containing $10^{-4} \mathrm{M}$ propylthiouracil until at least 90\% of counts were extracted. The extract was concentrated and applied to a paper chromatogram to determine the $\left[{ }^{125} \mathrm{I}\right] \mathrm{T}_{3}$ content. The concentration of $T_{3}$ in cytosol was computed from the product of the ${ }^{125} \mathrm{I}^{1} \mathrm{~T}_{3}$ cytosol/plasma ratio and the concentration of immunoassayable $T_{3}$ in the plasma. In the same serum and cytosolic fraction, we determined the level of $T_{3}$ by RIA using the technique of Surks et al. (21). In preliminary experiments we had determined that $T_{3}$ could be readily measured in the cytosol, as verified by excellent recovery of added $T_{3}$ without the requirement of a correction blank. To calculate the concentration of total $T_{3}$ in undiluted cytosol, we multiplied the concentration of $T_{3}$ in the diluted cytosol by the dilution factor, which was estimated to be $\left(4+V_{c}\right) / V_{c}$, where 4 represents the volume of buffer added per gram tissue, and $V_{c}$ represents the estimated volume of cytosol per gram tissue. Finally, the concentration of free $\mathrm{L}-\mathrm{T}_{3}$ could be estimated by division of the molar concentration of $T_{3}$ in cytosol by $b_{c}$, the binding power of cytosol as determined above.

Estimation of the nuclear free $T_{3}$ concentration $\left(F_{\mathrm{NL}}\right)$. A substantial body of information points to a reversible association of $T_{3}$ with specific nuclear nonhistone receptor sites (22). Moreover, there appears to be only one component upon Scatchard analysis of such receptor sites $(16,23)$. From the Law of Mass Action,

$$
F_{\mathrm{NL}}=\frac{T_{3} N}{\left(M-T_{3} N\right) k_{2}},
$$

where $T_{3} N$ is the molar concentration of the $T_{3}$ nuclear receptor complex, $M$ is the maximal binding capacity, and $k_{a}$ is the association constant of the nuclear sites as determined in vitro at $37^{\circ} \mathrm{C}(16) . T_{3} N /$ $M-T_{3} N$ represents the ratio of bound to free receptor sites. This could be derived for liver, kidney, and heart from our previous saturation studies in the intact rat (13). Because of the important contribution of local thyroxine $\left(T_{4}\right)$ to $T_{3}$ conversion in brain, we estimated this term in brain from the data recently presented by Crantz et al. (24).

Calculation of nuclear/cytoplasmic free $\left[{ }^{13.5} I\right] D-T_{3}$ ratios $\left(F_{\mathrm{ND}}^{*} /\right.$ $\left.F_{\mathrm{cD}}^{*}\right)$. Under tracer conditions,

$F_{\mathrm{ND}}^{*}=\frac{N_{\mathrm{D}}^{*}}{k_{\mathrm{ad}}\left(M-N_{\mathrm{L}}\right)}$,

where $N_{D}^{*}$ is the concentration of tracer $D-T_{3}$ per milligram DNA in the nucleus per kilogram tissue, $k_{\mathrm{aD}}$ is the association constant of $\mathrm{D}-\mathrm{T}_{3}$ for the nuclear sites measured in vitro, $M$ is the binding capacity per milligram DNA of nuclear sites per kilogram liver, and $N_{\mathrm{L}}$ is the nuclear $\mathrm{L}_{-} \mathrm{T}_{3}$ concentration per milligram DNA per kilogram tissue.

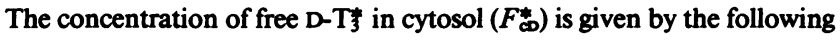
equation:

$F_{\mathrm{cD}}^{*}=\frac{C_{\mathrm{D}} \cdot(\rho)_{\mathrm{cD}}}{V_{\mathrm{d}} b_{\mathrm{cD}}}$

where $C_{\mathrm{D}}$ is the total cellular radioactivity per kilogram tissue and the subscript $\mathbf{D}$ designates the D-enantiomer.

Dividing Eq. 5 by Eq. 6 we obtain

$\frac{F_{\text {ND }}^{*}}{F_{\mathrm{CD}}^{*}}=\frac{N_{\mathrm{D}}^{*} V_{\mathrm{d}}\left(b_{\mathrm{CD}}\right)}{C_{\mathrm{D}}^{*} k_{\mathrm{aD}}(\rho)_{\mathrm{CD}}\left(M-N_{\mathrm{L}}\right)}=\frac{N_{\mathrm{D}}^{*}}{C_{\mathrm{D}}^{*}} \cdot \frac{1}{\beta_{\mathrm{D}} k_{\mathrm{aD}}} \cdot \frac{1}{\left(M-N_{\mathrm{L}}\right)}$, where $\beta_{\mathrm{D}}=(\rho)_{\mathrm{cD}} / V_{\mathrm{c}} b_{\mathrm{cD}}$. By analogy to Eq. 7, it can be shown that

$\frac{F_{\mathrm{NL}}^{*}}{F_{\mathrm{c}}^{*}}=\frac{N_{\mathrm{L}}^{*}}{C_{\mathrm{L}}^{*}} \frac{1}{\beta_{\mathrm{L}} \cdot k_{\mathrm{aL}}} \frac{1}{\left(M-N_{\mathrm{L}}\right)}$,

where the subscript $\mathrm{L}$ refers to the L-enantiomer. Since $\left(F_{\mathrm{cL}}^{*} / F_{\mathrm{NL}}^{*}\right)$ $=\left(F_{\mathrm{cL}} / F_{\mathrm{NL}}\right)$ it follows that

$(M-N)=\frac{N_{\mathrm{L}}^{*} F_{\mathrm{cl}}}{C_{\mathrm{L}}^{*} F_{\mathrm{NL}}} \frac{1}{\beta_{\mathrm{L}} \cdot k_{\mathrm{al}}}$.

Substituting into Eq. 7, we obtain

$\frac{F_{\mathrm{ND}}^{*}}{F_{\mathrm{cD}}^{*}}=\frac{N_{\mathrm{D}}^{*}}{C_{\mathrm{D}}^{*}} \cdot \frac{\beta_{\mathrm{L}} \cdot k_{\mathrm{al}}}{\beta_{\mathrm{D}} \cdot k_{\mathrm{aD}}} \cdot \frac{F_{\mathrm{NL}}}{F_{\mathrm{cL}}} \cdot \frac{C_{\mathrm{L}}^{*}}{N_{\mathrm{L}}^{*}}$

The values for $\beta_{\mathrm{L}}$ and $\beta_{\mathrm{D}}$ were computed and are listed in Table IV; the values for $k_{\mathrm{aD}}$ and $k_{\mathrm{aL}}$ were defined by Scatchard analysis of isolated nuclei. The ratio $F_{\mathrm{N} N} / F_{\mathrm{cL}}$ listed in Table $\mathrm{V}$ can be obtained from the quotient of $F_{\mathrm{NL}}$ (Table III) and $F_{\mathrm{cL}}$ (Table II). The ratios $N_{\mathrm{D}}^{*} / C_{\mathrm{D}}^{*}$ and $N_{\mathrm{L}}^{*} / C_{\mathrm{L}}^{*}$ were determined in experiments over $24 \mathrm{~h}$. After $0.5 \mathrm{~h}$, the $N^{*} / C^{*}$ ratio for all tissues was the same in all subsequent periods, which indicates rapid intracellular equilibration (18). The values for $M$ calculated from Eq. 9 and for $\mathrm{F}_{\mathrm{ND}}^{*} / \mathrm{F}_{\mathrm{cD}}^{*}$ calculated from Eq. 10 are presented in Table V. Chromatographic studies indicated that in the case of kidney nuclei, $\sim 30 \%$ of the radioactivity is in the form of an unidentified metabolite of $\mathrm{D}-\mathrm{T}_{3}$. The same proportion was observed at all times studied. Accordingly, all measurements of nuclear activity in kidney were corrected by the factor 0.70 . No contaminant was detected in the nuclear extracts of liver or heart.

\section{Results}

Measurement of free $T_{3}$ gradients between cytosol and plasma. Isotopic $\mathrm{T}_{3}$ measurements made at the equilibrium time point indicate that the tissue/plasma ratio is characteristic for each tissue and for each enantiomer (Table I). Thus, for $\mathrm{L}_{-} \mathrm{T}_{3}$ the tissue/plasma ratios were, in descending order, kidney, 10.7; liver, 9.8; heart, 3.2; and brain, 0.9. Since the characteristic tissue/plasma ratio is established before substantial quantities of $T_{3}$ are metabolized, we can assume as a first approximation that the equilibrium relationship between plasma and cells is determined by the individual binding components in each compartment and the level of free hormone in plasma and cells. Therefore, the higher tissue/plasma ratios in liver and kidney are due either to increased intracellular binding components or to the establishment of a high intracellular $T_{3}$ concentration as a result of the operation of transport processes, or to both. The free $\mathrm{L}-\mathrm{T}_{3}$ cytosolic/plasma ratio calculated as described in Methods reveals a relatively small gradient ranging from 0.9 in brain to 2.8 in liver. Because of the inherent experimental error in each of the multiple components of these calculations, it is difficult to be certain whether these values differ either from each other or from the value of 1 . The high tissue/plasma ratio for liver and kidney, however, appears not to be due primarily to an increased intracellular free hormone concentration. Rather, our data suggest that the higher total tissue uptake is related to increased intracellular $\mathrm{T}_{3}$ binding components. In the case of liver and kidney, the strong overall intracellular $\mathrm{L}_{-} \mathrm{T}_{3}$ binding is shared by cytosol since the level of binding as determined by equilibrium dialysis of cytosol is substantially greater than in brain, heart, and plasma (Table I).

An analysis of the $D-T_{3}$ results shows an even more striking difference among the tissue/plasma ratios in the four tissues 
Table I. Calculation of Radioactive Free Cytosolic/Plasma Ratios

\begin{tabular}{|c|c|c|c|c|c|c|c|c|c|}
\hline \multirow[b]{2}{*}{ Tissue } & \multicolumn{5}{|l|}{ L } & \multicolumn{4}{|l|}{ D } \\
\hline & $T / P$ & $V_{\mathrm{c}}$ & $\rho_{\mathrm{c}}$ & $b$ & $F_{\mathrm{d}} / F_{\mathrm{p}}$ & $T / P$ & $\rho_{\mathrm{c}}$ & $b$ & $F_{\mathrm{c}} / F_{\mathrm{p}}$ \\
\hline Liver & $\begin{array}{l}9.81 \pm 0.39^{*} \\
(33)\end{array}$ & $\begin{array}{l}0.28 \pm 0.01 \\
\quad(8)\end{array}$ & $\begin{array}{l}0.439 \pm 0.007 \\
\quad(18)\end{array}$ & $\begin{array}{l}691 \pm 23 \\
(8)\end{array}$ & 2.80 & $\begin{array}{l}27.48 \pm 2.23 \\
(32)\end{array}$ & $\begin{array}{l}0.604 \pm 0.009 \\
(10)\end{array}$ & $\begin{array}{c}335 \pm 12 \\
(8)\end{array}$ & 21.6 \\
\hline Kidney & $\begin{array}{l}10.69 \pm 0.56 \\
(24)\end{array}$ & $\begin{array}{l}0.49 \pm 0.02 \\
(8)\end{array}$ & $\begin{array}{l}0.596 \pm 0.007 \\
(18)\end{array}$ & $\begin{array}{c}1396 \pm 115 \\
(8)\end{array}$ & 1.17 & $\begin{array}{l}76.67 \pm 6.13 \\
(50)\end{array}$ & $\begin{array}{l}0.735 \pm 0.014 \\
\quad(10)\end{array}$ & $\begin{array}{c}231 \pm 6 \\
(8)\end{array}$ & 63.3 \\
\hline Heart & $\begin{array}{l}3.19 \pm 0.13 \\
(28)\end{array}$ & $\begin{array}{l}0.63 \pm 0.04 \\
(8)\end{array}$ & $\begin{array}{l}0.199 \pm 0.006 \\
(16)\end{array}$ & $\begin{array}{l}97 \pm 7 \\
(8)\end{array}$ & 1.31 & $\begin{array}{l}2.07 \pm 0.10 \\
(28)\end{array}$ & $\begin{array}{c}0.425 \pm 0.014 \\
(8)\end{array}$ & $\begin{array}{c}91 \pm 3 \\
(8)\end{array}$ & 1.58 \\
\hline Brain & $\begin{array}{l}0.90 \pm 0.05 \\
(36)\end{array}$ & $\begin{array}{l}0.54 \pm 0.02 \\
(8)\end{array}$ & $\begin{array}{l}0.335 \pm 0.012 \\
(16)\end{array}$ & $\begin{array}{l}82 \pm 5 \\
(8)\end{array}$ & 0.86 & $\begin{array}{l}0.20 \pm 0.02 \\
(35)\end{array}$ & $\begin{array}{c}0.505 \pm 0.015 \\
(8)\end{array}$ & $\begin{array}{c}81 \pm 4 \\
(8)\end{array}$ & 0.24 \\
\hline Plasma & - & - & - & $126 \pm 5$ & - & - & - & $103 \pm 9$ & - \\
\hline
\end{tabular}

$T / P$, tissue/plasma ratio (percentage dose per gram per percentage dose per milliliter). $V_{\mathrm{c}}$, volume of hormone-binding cytosol protein (liter per kilogram tissue). $\rho_{\mathrm{c}}$, fraction of total cellular radioactivity in cytosol. $b$, binding power of cytosol or plasma where $b=(1-D F / D F) \gamma$, where $D F$ is the dialysis fraction and $\gamma$ is the dilution factor. $F_{\mathrm{c}} / F_{\mathrm{p}}$, ratio of free hormone in cytosol and plasma. * Mean $\pm \mathrm{SEM}$; numbers in parentheses represent number of individual determinations.

studied. The highest ratio is exhibited by kidney, 76.7 ; followed by liver, 27.5; heart, 2.07; and brain, 0.20. These values indicate a highly selective accumulation of the D-enantiomer in liver and kidney. Moreover, the low tissue/plasma ratio in brain suggests a virtual exclusion of the D-enantiomer from this organ. Preferential accumulation of $D-T_{3}$ as compared with that of $\mathrm{L}^{-\mathrm{T}_{3}}$ in liver and kidney can be attributed almost completely to the accumulation of free $D-T_{3}$ in cytosol. This is apparent when the total tissue/plasma ratio of $D-T_{3}$ is compared with the corresponding free hormone ratio (Table I). Our results indicate, therefore, that the preferential entrance of $\mathrm{D}-\mathrm{T}_{3}$ into liver and kidney is not related to greater equilibrium binding of $\mathrm{D}-\mathrm{T}_{3}$ by intracellular compartments as compared with the binding of $\mathrm{D}-\mathrm{T}_{3}$ by plasma proteins. In the case of heart, the free hormone gradients for $L-$ and $D-T_{3}$ appear to be approximately the same. The fact that the total tissue/ plasma ratio of $L-T_{3}$ in the heart is $>1.0$ may be related to selective binding of $\mathrm{L}_{-} \mathrm{T}_{3}$ by noncytosolic components. As indicated above, the preferential entrance of $L-T_{3}$ as compared with that of $\mathrm{D}-\mathrm{T}_{3}$ into the brain is due to the apparent exclusion of free $D-T_{3}$ from this structure, because of either reduced fractional entrance or augmented exit of the $D-T_{3}$.

If the gravimetric content of $\mathrm{L}^{-\mathrm{T}_{3}}$ in cytosol and the cytosolic binding protein volume in cells are known, the absolute concentration of free $\mathrm{L}-\mathrm{T}_{3}$ in cytosol can be calculated (Table II). The cytosolic content of $T_{3}$ derived from plasma can be determined from the product of the ratio of radioactive $T_{3}$ in cytosol to radioactive $T_{3}$ in plasma at the equilibrium time point and the concentration of $T_{3}$ in plasma as determined by RIA. Alternatively, the total $T_{3}$ content in cytosol can be measured by direct RIA. The data presented in Table II show an excellent correspondence between the total $T_{3}$ content and the plasma-derived $T_{3}$ in liver, kidney, and heart but indicate that the level of $L-T_{3}$ in brain is substantially higher than that derived from plasma. These findings are precisely what one would anticipate from the earlier studies of Crantz et al. (24), who showed that $\sim 70 \%$ of brain $\mathrm{T}_{3}$ is derived from local $\mathrm{T}_{4^{-}}$ to- $\mathrm{T}_{3}$ conversion and that only the remaining $30 \%$ of the total cellular $T_{3}$ is derived from plasma. In contrast, the same group showed that virtually all of the $T_{3}$ in liver, kidney, and heart was derived from the plasma (25). As indicated in Table I, the binding power of cytosol of liver and kidney as determined by equilibrium dialysis was six- to sevenfold greater than that exhibited by plasma protein, whereas the binding by heart and brain cytosol was slightly less than that of plasma. The calculated free $T_{3}$ concentrations in liver, kidney, heart, and plasma based both on the direct RIA and the equilibrium dialysis varied over a remarkably small range as compared with the range of total cytosolic $T_{3}$ among the various tissues and plasma compartments analyzed. Thus, despite an almost 10-fold higher concentration of total $T_{3}$ in liver than in plasma, the concentration of free $T_{3}$ in cytosol was only 1.8-fold greater than that in plasma (Table II). The free cytosolic $T_{3}$ concentration of brain, however, was estimated to be 4.0 -fold higher than that of plasma and 2.3-fold higher than the concentration of free cytosolic $T_{3}$ in liver. The high ratio of free hormone in brain cytosol to that in plasma probably reflects the active local production of $T_{3}$ from $T_{4}$ in this tissue and a relatively slow equilibration of free $T_{3}$ between plasma and cytosol.

Table II. Estimation of Free Nonradioactive $\mathrm{T}_{3}$ in Cytosol and Plasma

\begin{tabular}{lccc}
\hline & \multicolumn{2}{l}{ Total cytosolic $\left(\times 10^{8} \mathrm{M}\right)$} & $\begin{array}{l}\text { Free cytosolic } \\
\left(\times 10^{11} \mathrm{M}\right)\end{array}$ \\
\cline { 2 - 3 } Tissue & Isotopic & Direct & \\
\hline Liver & $1.18 \pm 0.02^{*}$ & $1.09 \pm 0.04$ & $1.58 \pm 0.06$ \\
Kidney & $1.51 \pm 0.04$ & $1.65 \pm 0.05$ & $1.18 \pm 0.04$ \\
Heart & $0.123 \pm 0.006$ & $0.095 \pm 0.007$ & $0.98 \pm 0.14$ \\
Brain & $0.081 \pm 0.010$ & $0.295 \pm 0.011$ & $3.59 \pm 0.14$ \\
Plasma & & $0.114 \pm 0.005$ & $0.901 \pm 0.035$
\end{tabular}

\footnotetext{
* Mean \pm SEM, $n=4$
} 
Table III. Calculation of Nuclear Free L-T

\begin{tabular}{lcccc}
\hline & Liver & Kidney & Heart & Brain \\
\hline Association constant $\left(k_{\mathrm{a}}\right)\left(\times 10^{-8} L / M\right)$ & $9.65 \pm 0.65^{*}$ & $8.17 \pm 2.14$ & $9.90 \pm 0.10$ & $9.95 \pm 0.15$ \\
Percent saturation of receptors & $47 \ddagger$ & $35 \ddagger$ & $44 \ddagger$ & $90 \S$ \\
$T_{3} N /\left(M-T_{3} N\right)$ & 0.887 & 0.538 & 0.786 & 9.0 \\
Free nuclear $T_{3}\left(F_{\mathrm{N}}\right)\left(\times 10^{9} \mathrm{M}\right)$ & 0.92 & 0.66 & 0.79 & 9.0
\end{tabular}

$T_{3} N /\left(M-T_{3} N\right)$, ratio of occupied to unoccupied receptors. * Mean \pm SEM of two separate experiments. $\ddagger$ From reference 13 . $\S$ From reference 24 .

Nuclear/cytoplasmic free hormone gradients. Table III summarizes our calculations of free $T_{3}$ concentrations in the nuclei of various tissues. Our approach as outlined in Methods is based on the assumption that a reversible equilibrium exists between $T_{3}$ bound to specific nuclear sites and free $T_{3}$ in the surrounding medium. Evidence for a reversible association of $T_{3}$ with nuclear sites has been previously obtained (18) and is implicit in the use of Scatchard analysis to measure the number and affinity of nuclear receptors.

The calculated free $L-T_{3}$ concentration in the nucleus in each of the tissues was exceedingly high in relationship to the estimated free cytosolic $T_{3}$ concentration. The ratio between nuclear and cytoplasmic free $T_{3}$ concentrations was highest in brain with a value of 251 and, in descending order, of 80,58 , and 56 for heart, liver, and kidney, respectively. These gradients cannot be explained simply on the basis of statistical error. If our underlying assumptions are correct, they must represent the effect of an intracellular energy-requiring transport process. A vigorous transport process in brain appears to lead to the high degree of nuclear occupancy in this tissue, as first reported by Crantz et al. (24).

The data generated in our study have also allowed us to calculate the concentration gradient of free $\mathrm{D}-\mathrm{T}_{3}^{*}$ between nucleus and cytosol. The derivation of the equations used in these estimates is provided in Methods. The component factors and the results of the calculations are listed in Table IV. The nuclear/cytoplasmic ratios for $\mathrm{D}^{-\mathrm{T}_{3}^{*}}$ also vary from tissue to tissue but in all instances are less than the comparable values for $L-T_{3}^{*}$. In the brain, the determination of the nuclear/ cytoplasmic ratio was subject to considerable error because of the small amounts of $\mathrm{D}-\mathrm{T}_{3}^{*}$ that penetrated the cell. The radioactive counting per gram was approximately one-sixth of that achieved by L-T ${ }_{3}^{*}$. This was due to a threefold lower cellto-medium ratio for the D-enantiomer and the fact that, at the equilibrium time point, the concentration of $\mathrm{D}-\mathrm{T}_{3}^{*}$ in plasma was approximately one-half that of $L-T_{3}^{*}$. Because of the selective entrance of $L-T_{3}$, even a small contamination of $\left[{ }^{125} \mathrm{I}\right] \mathrm{L}-\mathrm{T}_{3}$ in the dose of $\left[{ }^{125} \mathrm{I}\right] \mathrm{D}-\mathrm{T}_{3}$ might make an important contribution to the intracellular brain radioactivity, especially at the nuclear level. Thus, it is possible that the estimated nuclear/cytoplasmic ratio for $D-T_{3}$ in brain represents an overestimate.

From Eq. 9 and percent occupancy cited in Table III we can also calculate the binding capacity per milligram of DNA for individual tissues. The results of these calculations are summarized in Table V. In general, the calculated values compare favorably to those directly determined by saturation analyses in the intact animal. Thus, the calculated binding capacity was as follows (picomoles per milligram DNA): liver, 0.83 ; kidney, 1.99 ; brain, 0.44 ; and heart, 0.66 , which are in remarkable agreement with direct measurements previously reported: liver, 0.94; kidney, 0.81; brain, 0.41; and heart, 0.61 (13).

\section{Discussion}

In the present report we have examined the factors responsible for the partition of $\left[{ }^{125} \mathrm{I}\right] \mathrm{D}$ - and $\left[{ }^{125} \mathrm{I}\right] \mathrm{L}-\mathrm{T}_{3}$ between selected tissues and plasma and the intracellular distribution between

Table IV. Calculation of Nuclear/Cytoplasmic Free $D-T_{3}^{*}$

\begin{tabular}{|c|c|c|c|c|c|c|c|}
\hline Tissue & $\beta_{\mathrm{L}}$ & $\beta_{\mathrm{D}}$ & $k_{\mathrm{aL}}$ & $k_{\mathrm{DD}}$ & $\left.(N)^{*}\right) /(C \xi)$ & $\left(N_{\mathrm{B}}^{*}\right) /\left(C_{\mathrm{B}}^{\mathrm{*}}\right)$ & $\left(F_{\mathrm{D}}\right) /\left(F_{\mathrm{D}}\right)$ \\
\hline Liver & 2.27 & 6.44 & $\begin{array}{l}9.65 \pm 0.65 \\
(2)\end{array}$ & $\begin{array}{l}5.76 \pm 0.91 \\
(2)\end{array}$ & $\begin{array}{l}0.0559 \pm 0.0081 \\
\quad(21)\end{array}$ & $\begin{array}{l}0.00601 \pm 0.00060 \\
\quad(21)\end{array}$ & 3.70 \\
\hline Kidney & 0.87 & 6.49 & $\begin{array}{l}8.17 \pm 2.14 \\
(2)\end{array}$ & $\begin{array}{l}5.90 \pm 1.14 \\
(2)\end{array}$ & $\begin{array}{l}0.0257 \pm 0.0023 \\
\quad(12)\end{array}$ & $\begin{array}{l}0.00381 \pm 0.00032 \\
\quad(12)\end{array}$ & 1.54 \\
\hline Heart & 3.71 & 7.95 & $\begin{array}{l}9.90 \pm 0.10 \\
(2)\end{array}$ & $\begin{array}{l}6.74 \pm 0.21 \\
\quad(2)\end{array}$ & $\begin{array}{l}0.1090 \pm 0.0091 \\
\quad(15)\end{array}$ & $\begin{array}{l}0.0492 \pm 0.0049 \\
(15)\end{array}$ & 24.9 \\
\hline Brain & 7.95 & 12.73 & $\begin{array}{l}9.95 \pm 0.15 \\
\text { (2) }\end{array}$ & $\begin{array}{l}9.39 \pm 0.22 \\
\text { (2) }\end{array}$ & $\begin{array}{l}0.0876 \pm 0.0115 \\
(14)\end{array}$ & $\begin{array}{l}0.0571 \pm 0.0118 \\
(14)\end{array}$ & 108.6 \\
\hline
\end{tabular}

$\left(N_{\mathrm{L}}^{*}\right) /\left(C_{\mathrm{L}}^{*}\right)$ and $\left(N_{\mathrm{D}}^{*}\right) /\left(C_{\mathrm{D}}^{*}\right)$, nuclear/cytoplasmic radioactivity concentration ratio per milligram DNA of $\mathrm{L}-$ and $\mathrm{D}-\mathrm{T}_{3}$, respectively. $\left(F_{\mathrm{ND}}^{*}\right) /\left(F_{\mathrm{D}}^{*}\right)$, nuclear/cytoplasmic free [ $\left.{ }^{125} \mathrm{I}\right] \mathrm{D}-\mathrm{T}_{3}$ concentration ratio. $\beta=\rho_{\mathrm{c}} / V_{\mathrm{c}} b_{\mathrm{c}}\left(\times 10^{3}\right.$ liters $\left./ \mathrm{kg}\right) . \quad k_{\mathrm{aL}}$ and $k_{\mathrm{aD}}$, affinity constants $\left(\times 10^{-8} \mathrm{M}^{-1}\right)$ of $\mathrm{L}-$ and $\mathrm{D}-\mathrm{T}_{3}$, respectively. See Methods for derivation of computations. To calculate the fraction of total cellular radioactivity associated with the nucleus values of $\left(N_{\mathrm{t}}^{*}\right) /\left(C^{*}\right)$ or $\left(N_{\mathrm{D}}^{*}\right) /\left(C_{\mathrm{D}}^{*}\right)$ may be multiplied by the following average DNA concentrations (milligrams per gram): liver, 2.90; kidney, 4.93; heart, 2.01; and brain, 1.55. * Mean \pm SEM; numbers in parentheses represent number of experiments. 
Table V. Summary of Free Hormone

Gradients and Calculated Binding Capacity

\begin{tabular}{|c|c|c|c|c|c|}
\hline \multirow[b]{2}{*}{ Tissues } & \multirow{2}{*}{$\begin{array}{l}\text { Binding } \\
\text { capacity }\end{array}$} & \multicolumn{2}{|c|}{$\left(F_{\mathrm{c}} / F_{\mathrm{p}}\right)$} & \multicolumn{2}{|l|}{$\left(F_{\mathrm{N}} / F_{\mathrm{c}}\right)$} \\
\hline & & L & D & L & D \\
\hline & pmol/mg & & & & \\
\hline Liver & 0.87 & 2.80 & 21.6 & 58.2 & 3.70 \\
\hline Kidney & 0.994 & 1.17 & 63.3 & 55.9 & 1.54 \\
\hline Heart & 0.658 & 1.49 & 2.07 & 80.6 & 24.9 \\
\hline Brain & 0.44 & 0.90 & 0.32 & 251.0 & 108.6 \\
\hline
\end{tabular}

Binding capacity was calculated from Eq. 9 by use of data in Tables III and IV.

nuclear and extranuclear compartments. Our results extend our previous findings, which indicate a stereospecific uptake of $L-T_{3}$ by liver and heart nuclei in the living animal despite the similar nuclear affinities for these enantiomers in vitro (10). The present report clearly shows that the differential accumulation of these enantiomers is highly characteristic of a given tissue but that in each there is a preferential nuclear uptake of the L-enantiomer in the intact animal.

Our analysis suggests the existence of two stereospecific transport systems, one leading to the accumulation of $\mathrm{L}$ - and $\mathrm{D}-\mathrm{T}_{3}$ by the cells as a whole and the other involved in the selective concentration of $\mathrm{L}-\mathrm{T}_{3}$ by the nuclei. Our conclusions are based on the estimation of the equilibrium free hormone concentrations in plasma, cytosol, and nucleus and the assumption of the exchange processes represented in Fig. 1. We assumed that the selective accumulation of radioactive $D$ - and L-T $T_{3}$ by specific cellular and subcellular compartments is a function both of the concentration of free aqueous hormone with which specific particulate components equilibrate and of the specific binding characteristics of such compartments. In order to determine the concentration of free hormone in plasma, conventional equilibrium dialysis was performed and the mass of circulating total $T_{3}$ was determined by RIA. Similarly, we estimated the concentration of free $T_{3}$ in the nuclear fraction from the results of the Scatchard analysis of isolated nuclei and the known fractional nuclear occupancy in euthyroid animals. We have also assumed that the cytosolic component measured represents a uniform compartment that is in direct kinetic contiguity with the nucleus. We further assumed that there is no significant redistribution of radioactivity from one fraction to another in the course of subcellular fractionation. In previous studies, we have provided evidence that such redistribution does not occur between nuclear and extranuclear compartments at $0^{\circ} \mathrm{C}(9)$. In more recent preliminary experiments we have also shown that the rate of dissociation of $T_{3}$ from the particulate fraction is slow enough at $0^{\circ} \mathrm{C}$ so as not to introduce any serious error into our calculation. Even if, for the sake of argument, we assumed to be true the unlikely possibility that all of the cellular radioactivity in the non-nuclear fraction is concentrated in the cytosol, there would remain an important gradient of free $T_{3}$ between the nuclear and cytoplasmic compartments.

Our findings have also shown that the preferential uptake of $D-T_{3}$ by the kidney and liver as a whole cannot be attributed to preferential binding of the D-enantiomer by any of the major subcellular constituents. To the contrary, the cytosolic proteins bound $\mathrm{L}$ - more avidly than $\mathrm{D}^{-T_{3}}$. Similarly, from the fractional distribution of radioactive $T_{3}$ in the other subcellular fractions, we inferred that there was no preferential binding of $D_{-} \mathrm{T}_{3}$ by any subcellular fractions. These considerations are simply another way of stating our basic conclusion that, in liver and kidney, preferential uptake of $D-T_{3}$ is due to the operation of a stereospecific transport system responsible for the translocation of $\mathrm{D}-\mathrm{T}_{3}$ from plasma to cytosol.

The preferential accumulation of $\mathrm{D}-\mathrm{T}_{3}$ by liver and kidney contrasts markedly with the results in brain and heart. In heart, the free $L$ - and $D-T_{3}$ cytosol/plasma gradients were similar and only slightly greater than 1.0 , whereas we consistently showed a reverse cytosol/plasma gradient in brain with a value of 0.32 for $D-T_{3}$, a value significantly less than 1.0.

Our findings suggest that the stereospecific transport of $T_{3}$ across plasma membranes is characteristic of each cell type in this process. With $D-T_{3}$, the high free hormone gradients in liver and kidney (21.6 and 63.3, respectively) suggest the participation of an energy-dependent process. The smaller ratio with $\mathrm{L}^{-\mathrm{T}_{3}}(1.17$ to 2.80$)$ raises the possibility that the observed deviation from unity may simply represent experimental error in measurement of individual components used to calculate the gradient. It is possible, therefore, that in the case of $L-T_{3}$ an energy-requiring process is not necessary for transport from plasma to cytosol.

Despite the obvious stereospecific factors involved in the transport of $L-T_{3}$ from plasma to cytosol there is remarkably little alteration in the partition of $L-T_{3}$ between plasma and cells with increasing doses of $\mathrm{L}_{-} \mathrm{T}_{3}$. Only with very large doses of the D-enantiomer was it possible to inhibit to some extent the fractional accumulation of this iodothyronine by kidney and liver (data not shown). Our in vivo findings with $\mathrm{L}^{-\mathrm{T}_{3}}$ contrast markedly with other reports of in vitro systems, suggesting that there is participation of limited capacity, high affinity binding sites (3-6). Moreover, the lack of effect of large doses on transport makes it difficult to determine that facilitated transport is involved. Our data are perhaps most compatible with the concept that there is a virtual infinitude of stereospecific binding sites involved in transmembrane transport. The possibility should also be considered that there are two processes involved in $T_{3}$ transport, simple diffusion for $\mathrm{L}_{-} \mathrm{T}_{3}$ which may not be stereospecific and a specialized transport system involved in the movement of $\mathrm{D}-\mathrm{T}_{3}$. However, the finding of cytosolic/plasma gradients of free $T_{3}<1.0$ in brain would be incompatible with the concept of free diffusion in this cell type. It is intriguing to speculate about a possible relationship between $D-T_{3}$ accumulation by liver and kidney and the well-known presence of D-amino oxidases in these tissues.

In contrast to the modest cytosolic/plasma free $\mathrm{L}_{-} \mathrm{T}_{3}$ ratios in the various tissues analyzed, our results point to a very steep free $T_{3}$ gradient from cytosol to nucleus. Our calculation of the free $L-T_{3}$ concentration in the nucleus is based on the generally accepted assumption that there is a reversible equilibrium between free $T_{3}$ and $T_{3}$ bound to the specific nuclear sites. We can estimate the ambient free $T_{3}$ concentration in the nucleus from the association constant as determined by saturation analysis of isolated nuclei at $37^{\circ} \mathrm{C}$ and the fraction of the total sites occupied under euthyroid conditions. The nuclear/cytosolic free $T_{3}$ ratios calculated in this fashion varied 
from 57 in kidney to 251 in brain. Such high values suggest the participation of active transport in establishing these gradients.

The establishment of a gradient from cytosol to nucleus may explain the discrepancy between the estimates of nuclear affinity for $L-T_{3}$ based on equilibration experiments in the intact animal and the results of in vitro measurements in isolated nuclei or solubilized receptors incubated at $37^{\circ} \mathrm{C}$. Thus, in our earlier studies we estimated that the nuclear affinity of $\mathrm{T}_{3}$ was $4.7 \times 10^{11} \mathrm{M}^{-1}$, whereas the in vitro estimates by us and others show a range of $\sim 5 \times 10^{8}$ to $5 \times 10^{9}(9,16$, $26,27)$. For in vivo calculations, however, we tacitly assumed that the concentration of free $T_{3}$ throughout the cell was uniform and equivalent to the concentration of free $T_{3}$ in the plasma. In addition, the concept that exchange of free $T_{3}$ between cytosol and nuclear compartment proceeds by simple diffusion was buttressed by the rapid equilibration of $T_{3}$ in medium with specific receptors in isolated nuclei in vitro. In such preparations, addition of metabolic inhibitors had no effect on the partition of $T_{3}$ between specific nuclear sites and the medium (9).

The present set of experiments has induced us to revise our concepts of the mechanism underlying the exchange process in vivo. The exchange of $T_{3}$ with nuclei in vitro probably is not an appropriate model for the exchange in the living animal. Thus, in vitro exchange probably is a result of simple diffusion and is not contingent upon the expenditure of metabolic energy. In the intact cell, however, such a diffusion process either does not occur at all or is supplemented by energy-producing processes. Presumably, in the process of subcellular fractionation, the structural basis of the mechanism responsible for $\mathrm{T}_{3}$ transport from cytosol to nucleus is disrupted.

The precise nature of the transport mechanism responsible for the cytosolic/nuclear gradient remains speculative. There is very little precedent for other transport systems involved in the translocation of ions, metabolites, and other hormones from the cytosol to the nucleus. However, an earlier report by Alfrey et al. suggested that active transport of amino acids between cytosol and nucleus depended upon the activity of Na-K ATPase (28). Since these studies were carried out before the development of current methods for subcellular fractionation techniques, it is conceivable that some of the results may have been due to contaminating subcellular fractions. On the other hand, it appears equally plausible that the methods now used for separating nuclei result in the detachment of important components involved in the putative transport mechanisms.

The nuclear/cytoplasmic free hormone ratio for $D-T_{3}$ was estimated from Eq. 10 and thus depended upon the assumption of multiple biologic constants. Nevertheless, the results given in Table IV and summary Table $\mathrm{V}$ clearly show that in every tissue there appears to be a substantially higher gradient for $L-$ than for $D-T_{3}$ between cytosol and the nucleus. The greater ratio of $L$ - than of $D-T_{3}$ is particularly evident for liver and kidney and less pronounced for heart and brain. Since brain and heart did not concentrate $D-T_{3}$ it is possible that a small percentage of contaminating $L-T_{3}$ in the $D-T_{3}$ preparations may have been responsible for a significant fraction of the accumulated radioactivity. Additional experiments are required to exclude this possibility.

It is interesting that Eq. 9 allows us to calculate the unoccupied binding capacity per milligram of DNA. From this value and the knowledge of the fraction of total sites occupied in the euthyroid animal, we can compute the total nuclear binding capacity as well. The results of these calculations provided in Table $\mathrm{V}$ indicate a remarkable degree of agreement with the binding capacities as determined in saturation experiments in whole animals (13). The general internal consistency of these data support the validity of the underlying assumptions and approaches used in these studies.

Finally, an alternative explanation for our nuclear data should be considered, namely that the binding affinity of the nuclear sites as determined in vitro represents a marked underestimation of the affinity operative under in vivo conditions. One could postulate that essential ionic and metabolic elements present in the nucleus under in vivo conditions are removed in the process of subcellular fractionation. Such an explanation, however, does not seem likely for the following reasons. One would be compelled to postulate that subcellular fractionation resulted not only in diminished affinity but also in a loss of stereospecificity. Moreover, if subcellular fractionation had resulted in a 50-fold loss in affinity of the specific sites it would be impossible to detect the receptor in in vitro incubation experiments. The ratio of specific to nonspecific binding both in vivo and in vitro is $\sim 20$ to 1 . Nevertheless, rigorous elimination of this possibility must await the development of specific in vitro systems that will allow direct study of the transport system and the ability of specific reagents to inhibit such a transport system.

The nuclear transport system may be regulated under a variety of pathophysiological conditions. Thus, our results may have important clinical implications. Previous reports have suggested that the peripheral thyroid hormone resistance of tissues, for instance, may be due to a defect in cellular transport of hormone $(29,30)$. The possibility that defects occur in nuclear transport should also be considered. Our findings may be relevant to the pharmacologic problem of developing analogues with selective tissue effects. Our data indicate that despite previously reported agreement between biologic activity and nuclear binding (22), appropriate comparison of thyroid hormone analogues can only be made by reference to in vivo systems. This has been demonstrated not only by this report but by studies carried out by Emmet and co-workers (31). Thus, differential penetration of the cytoplasm and the nucleus by thyroid hormone analogues must be taken into account in correlating hormonal biologic effects with nuclear occupancy. We should also consider the possibility that analogous transport systems are involved in the transport of other hormones and metabolites to the nucleus.

\section{Acknowledgments}

We thank our colleague Dr. Cary N. Mariash for useful discussions, comments, and suggestions. We also thank Mr. Hobie Pharis and Ms. Barbara Dodge for their expert help in the preparation of the manuscript and Mr. Robert Gunville and Ms. Ana Martinez-Tapp for their technical support.

This work was supported by National Institutes of Health grant AM19812.

\section{References}

1. Oppenheimer, J. H., M. I. Surks, and H. L. Schwartz. 1969. The metabolic significance of exchangeable cellular thyroxine. Recent Prog. Horm. Res. 25:381-414. 
2. Lein, A., and R. M. Dowben. 1961. Uptake and binding of thyroxine and triiodothyronine by rat diaphragm in vitro. Am. J. Physiol. 200:1029-1031.

3. Rao, G. S., J. Eckel, M. L. Rao, and H. Breuer. 1976. Uptake of thyroid hormone by isolated rat liver cells. Biochem. Biophys. Res. Commun. 73:98-104.

4. Rao, G. S., M. L. Rao, A. Thilmann, and H. D. Quednau. 1981. Study of fluxes at low concentrations of L-triiodothyronine with rat liver cells and their plasma-membrane vesicles. Biochem. J. 198:457466.

5. Krenning, E. P., R. Docter, H. F. Bernard, T. J. Visser, and G. Hennemann. 1978. Active transport of triiodothyronine $\left(T_{3}\right)$ into isolated rat liver cells. FEBS (Fed. Eur. Biochem. Soc.) Lett. 91:113116.

6. Krenning, E. P., R. Docter, B. Bernard, T. Visser, and G. Hennemann. 1981. Characteristics of active transport of thyroid hormone into rat hepatocytes. Biochim. Biophys. Acta 676:314-320.

7. Cheng, S. Y., F. R. Maxfield, J. Robbins, M. C. Willingham, and I. H. Pastan. 1980. Receptor-mediated uptake of 3,3',5 triiodo-Lthyronine by cultured fibroblasts. Proc. Natl. Acad. Sci. USA. 77:34253429.

8. Horiuchi, R., S. Y. Cheng, M. Willingham, and I. Pastan. 1982. Inhibition of the nuclear entry of 3,3',5 triiodo-L-thyronine by monodansylcadaverine in $\mathrm{GH}_{3}$ cells. J. Biol. Chem. 257:3139-3144.

9. Surks, M. I., D. H. Koerner, and J. H. Oppenheimer. 1975. In vitro binding of L-triiodothyronine to receptors in rat liver nuclei. Kinetics of binding extraction properties and lack of requirement for cytosol proteins. J. Clin. Invest. 55:50-60.

10. Schwartz, H. L., D. Trence, J. H. Oppenheimer, N. S. Jiang, and D. B. Jump. 1983. Distribution and metabolism of $L-$ and D-triiodothyronine $\left(\mathrm{T}_{3}\right)$ in the rat: preferential accumulation of L-T by hepatic and cardiac nuclei as a probable explanation of the differential biological potency of $\mathrm{T}_{3}$ enantiomers. Endocrinology. 113:1236-1243.

11. Bellabarba, D., R. Peterson, and K. Sterling. 1968. An improved method for the chromatography of iodothyronines. J. Clin. Endocrinol. Metab. 28:305-307.

12. Hay, I. D., T. M. Annesley, N. S. Jiang, and C. A. Gorman. 1981. Simultaneous determination of $D-$ and L-thyroxine in human serum by ligand chromatography with electrochemical detection. $J$. Chromatogr. 226:383-390.

13. Oppenheimer, J. H., H. L. Schwartz, and M. I. Surks. 1974. Tissue differences in the concentration of triiodothyronine nuclear binding sites in the rat: liver, kidney, pituitary, heart, brain, spleen, and testis. Endocrinology. 95:897-903.

14. Giles, K. W., and A. Meyers. 1965. An improved diphenylamine method for the estimation of deoxyribonucleic acid. Nature (Lond.). 206:93.

15. Oppenheimer, J. H., R. Squef, M. I. Surks, and H. Hauer. 1963. Binding of thyroxine by serum proteins evaluated by equilibrium dialysis and electrophoretic techniques. Alterations in non-thyroidal illness. J. Clin. Invest. 42:1769-1781.

16. Schuster, L. D., H. L. Schwartz, and J. H. Oppenheimer. 1979. Nuclear receptors for 3,5,3'-triiodothyronine in human liver and kidney: characterization, quantitation and similarities to rat receptors. Endocrinology. 48:627-632.

17. Oppenheimer, J. H., and M. I. Surks. 1974. Quantitative aspects of hormone production, distribution, metabolism and activity. In Handbook of Physiology. Vol. III. M. A. Greer and D. H. Solomon, editors. American Physiology Society, Washington DC. 192.

18. Oppenheimer, J. H., H. L. Schwartz, D. Koerner, and M. I. Surks. 1974. Limited binding capacity sites for L-triiodothyronine in rat liver. Nuclear-cytoplasmic interrelation, binding constants, and cross-reactivity with L-thyroxine. J. Clin. Invest. 53:768-777.

19. Oppenheimer, J. H., H. L. Schwartz, H. C. Shapiro, G. Bernstein, and M. I. Surks. 1970. Differences in primary cellular factors influencing the metabolism and distribution of 3,5,3'-L-triiodothyronine and thyroxine. J. Clin. Invest. 49:1016-1024.

20. Oppenheimer, J. H., and M. I. Surks. 1964. Determination of free thyroxine in human serum: a theoretical and experimental analysis. J. Clin. Endocrinol. Metab. 24:785-793.

21. Surks, M. I., A. R. Schadlow, and J. H. Oppenheimer. 1972. A new radioimmunoassay for L-triiodothyronine. Measurements in thyroid disease and in patients maintained on hormonal replacement. J. Clin. Invest. 51:3104-3113.

22. Oppenheimer, J. H. 1979. Thyroid hormone action at the cellular level. Science (Wash. DC). 203:971-979.

23. Samuels, H. H., J. S. Tsai, J. Casanova, and F. Stanley. 1974. Thyroid hormone action. In vitro characterization of solubilized nuclear receptors from rat liver and cultured $\mathrm{GH}_{1}$ cells. J. Clin. Invest. 54:853865.

24. Crantz, F. R., J. E. Silva, and P. R. Larson. 1982. An analysis of the sources and quantity of 3,5,3'-triiodothyronine specifically bound to nuclear receptors in rat cerebral cortex and cerebellum. Endocrinology. 110:367-375.

25. Silva, J. E., T. E. Dick, and P. R. Larsen. 1978. Contribution of local tissue thyroxine monodeiodination to the nuclear 3,5,3'triiodothyronine in pituitary, liver and kidney of euthyroid rats. Endocrinology. 103:1196-1207.

26. Mann, D. N., and M. I. Surks. 1983. 5,5'-diphenylhydration decreases specific $3,5,3^{\prime}$-triiodothyronine $\left(T_{3}\right)$ binding by rat hepatic nuclear $T_{3}$ receptors. Endocrinology. 112:1723-1731.

27. DeGroot, L. J., and J. Torresani. 1975. Triiodothyronine binding to isolated liver cell nuclei. Endocrinology. 96:357-369.

28. Allfrey, V. G., R. Meudt, J. W. Hopkins, and A. E. Mirsky. 1981. Sodium-dependent "transport" reactions in the cell nucleus and their role in protein and nucleic acid synthesis. Proc. Natl. Acad. Sci. USA. 47:907-932.

29. Chait, A., R. Kanter, W. Green, and M. Kenny. 1982. Defective thyroid hormone action in fibroblasts cultured from subjects with the syndrome of resistance to thyroid hormones. J. Clin. Endocrinol. Metab. 54:767-772.

30. Worstman, J., B. N. Premachandra, K. Williams, K. Burman, I. D. Hay, and P. J. Davis. 1983. Familial resistance to thyroid hormone associated with decreased transport across the plasma membrane. Ann. Intern. Med. 98:904-909.

31. Emmet, J. C., D. Ellis, N. J. Pearce, V. P. Shah, and A. H. Underwood. 1982. 3'-acetyl-3,5-triiodothyronine: highly active thyromimetic with low receptor affinity. Proc. Annu. Meeting Am. Thyroid Assoc., 58th, Quebec. T-36. (Abstr.) 